\title{
Algorithms Air Conditioning Air Filter Detection System for Electric Energy Savings
}

\author{
Ali A. S. Ramschie \\ Department of Computer \\ Engineering \\ Manado State Polytechnic
}

\author{
Johan F. Makal \\ Department of Electrical \\ Engineering \\ Manado State Polytechnic
}

\author{
Veny V. Ponggawa \\ Department of Computer \\ Engineering \\ Manado State Polytechnic
}

\begin{abstract}
Increased consumption of electrical energy consumption of air conditioning equipment can be caused because the air filter was dirty. This is because the operation of the compressor continuously to reach the appropriate temperature set point. To overcome this, it is necessary to add a system that can detect the impurities of air conditioning air filters to prevent the squandering of electricity. The system created would turn off air conditioning work and provide information to the user through the alarm and the display on the LCD screen that the air conditioning needs to be treated. In the manufacture of this system, created an algorithm built into the microcontroller which serves to operate the working of the whole system. From the results of the testing algorithm detection system air filter Air Conditioning conducted, found that when the air filter equipment Air Conditioning has indicated dirty, then the system will disable the working Air Conditioning and activate alarms as information to the user that the equipment needs to be treated. Besides, it is also the system will inform the user via an LCD display that Air Conditioning needs to be done in connection with the treatment has indicated dirty air filter.
\end{abstract}

\section{Keywords}

Algorithm, Air Conditioning, Air Filter, Energy Saving.

\section{INTRODUCTION}

To get quality work optimal air conditioning, good treatment and the right of each component into the main condition for optimal cooling process.

One of the things that can affect the quality of work of air conditioning is the air filter that has been soiled, where air is sucked through the air filter has been hampered by a buildup of dust, so that the air circulation becomes impaired. This can increase the electrical energy consumption of air conditioning equipment for the compressor will work continuously for air conditioning is still functioning.

The system is integrated in the manufacture of detection systems filter water air conditioning using a microcontroller ATMega 8535 which functions as a regulator of work the whole system [5], the current sensor ACS712 which serves as a detector increase in the current consumption of the user equipment air conditioning [1], crystal liquid display (LCD) that serves to display information relating to the state of the air conditioning, buzzer which functioned as an alarm to inform that the air conditioning needs to be taken care, electronic components as a supporting component in the manufacture of control systems [2],

To run the air filter detection system of air conditioning, it takes the program is embedded into the microcontroller ATMega 8535 The simulated through the program Proteus [8], where the software used for the preparation of the program is CodeVisionAVR [3], with reference to a flowchart (flowchart) made [7].

Studies related to this paper has much to do as is done by: 1) Chiou. C.B et al, (2008), published in the journal Energy and Buildings, with the title The study of energy saving strategy for direct expansion air conditioning system, where the research was related with energy saving procedures in DX Air conditioning system, with periodic downtime method, namely by adjusting the period of operation of the system and the dead period of two air conditioning systems [4]. 2) Widell et al, (2009), published in the International Journal of Refrigeration titled Reducing power consumption in multi compressor refrigeration systems, using linear programming models to minimize the energy consumption of electric compressor, the compressor operation will be optimal in accordance with the load required [9]. 3) Zhou et al (2007) study, published in the journal Energy and Buildings, entitled Energy simulation in the variable refrigerant flow airconditioning system under cooling conditions, do some research in terms of comparison of energy expenditure generated in the air conditioning system with three different methods, the system of variable refrigerant flow (VRF) systems, variable air volume (VAV) systems and fan-coil plus fresh water (FPFA). The study was conducted by simulation using Energy Plus software. The simulation results showed that the energy-saving potential of VRF system reached $22.2 \%$ and $11.7 \%$, compared with VAV system and FPFA system [10]. 4) Sudirman and Winaya (2010), which was published in the National Conference on Hotel Engineering, entitled Effects of Variation Round Against Compressor Shaft Performance Systems, Research done by changing the frequency of electricity supplied to the compressor using a variable speed driver (VSD). Showed that the lower the rotational speed compressor, refrigeration system COP value will rise, and vice versa. However, the lower frequencies are used, the electrical energy consumption will also lower the [6].

\section{METHODOLOGY}

The method used in this paper is a method of design that starts from the design of software by using a flowchart as algorithms the system works, the manufacture of coding the program using the software CodeVisionAVR, followed by testing the algorithm using software Proteus to get results as a working system algorithm.

\subsection{Study Design Module}

Design Module In the block diagram, the detection system of air conditioning air filters on the show in Figure 1. 


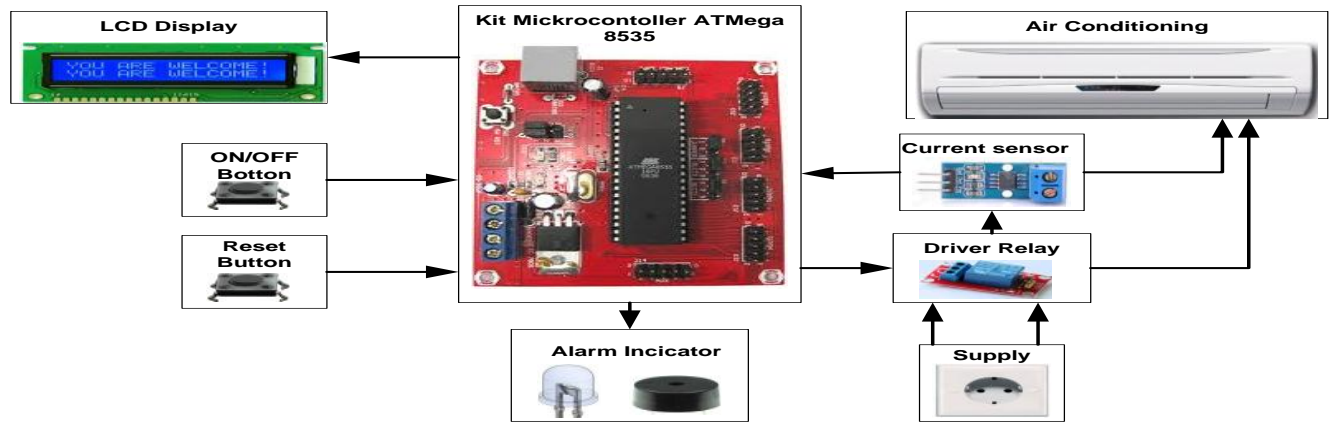

Fig. 1 Blcok diagram system

Information :

- Kit ATMega 8535 microcontroller serves as a regulator of the whole system work.

- The on / off function to activate and deactivate the system works.

- Reset button, it functions to reset the system at the time indicated air filter air conditioning was dirty (marked by an active alarm indicator).

- Alarm indicator, serves as a medium of information if the air filter dirty air conditioning has indicated, through sound alarms and LED blink.

- Driver relay, serves as a driver to activate and deactivate the air conditioning work.

- Current sensor, serves as a conduit of information to the microcontroller ATMega 8535 with respect to the amount of current consumed air conditioning equipment.

- LCD display, function as a medium of information on the state of air filters and the amount of electrical energy consumption of air conditioning equipment.

\subsection{Flowchart System (Algorithm)}

Flow charts detection system air filters of air conditioning is shown in Figure 2.

Description algorithm of the system as follows:

- The initial stage of the system will read the state on the button to activate the whole system.

- Once the system is active, air conditioning equipment will be activated via a relay driver circuit.

- $\quad$ Then the system will read state whether the off button is pressed or not, if pressed, the system will turn off the air conditioning working, then the system back to stage 1 . If the off button is not pressed, then the system leading to the next stage.

- The next stage, read current sensor data through the ADC then compare it to the set point value.

- If the current sensor data is in the range set point value when the compressor is in off state (only indoor work), then the system will calculate the consumption of electric energy (Wh) and the amount paid (IDR) and display via the LCD.

- If the current sensor data is in the range set point value when the compressor is currently turned on (out door, and indoor work), then the system will calculate the consumption of electric energy (Wh) and the amount paid (IDR) and display via the LCD.

- If the current sensor data is greater than the set point value when the rising consumption of electric current for the compressor work long due to soiling the air filter of air conditioning, the system will turn off the air conditioning work and activate alarms and display information through the LCD that has a dirty air filter.

- Then the system will read the state of the reset button to deactivate the alarm and informed that the system must be turned off to do a cleaning of dirty air filter of air conditioning equipment.

- After the process of air conditioning maintenance carried out, the operation of the system back to the early stages of reading on the state of the button to activate the system.

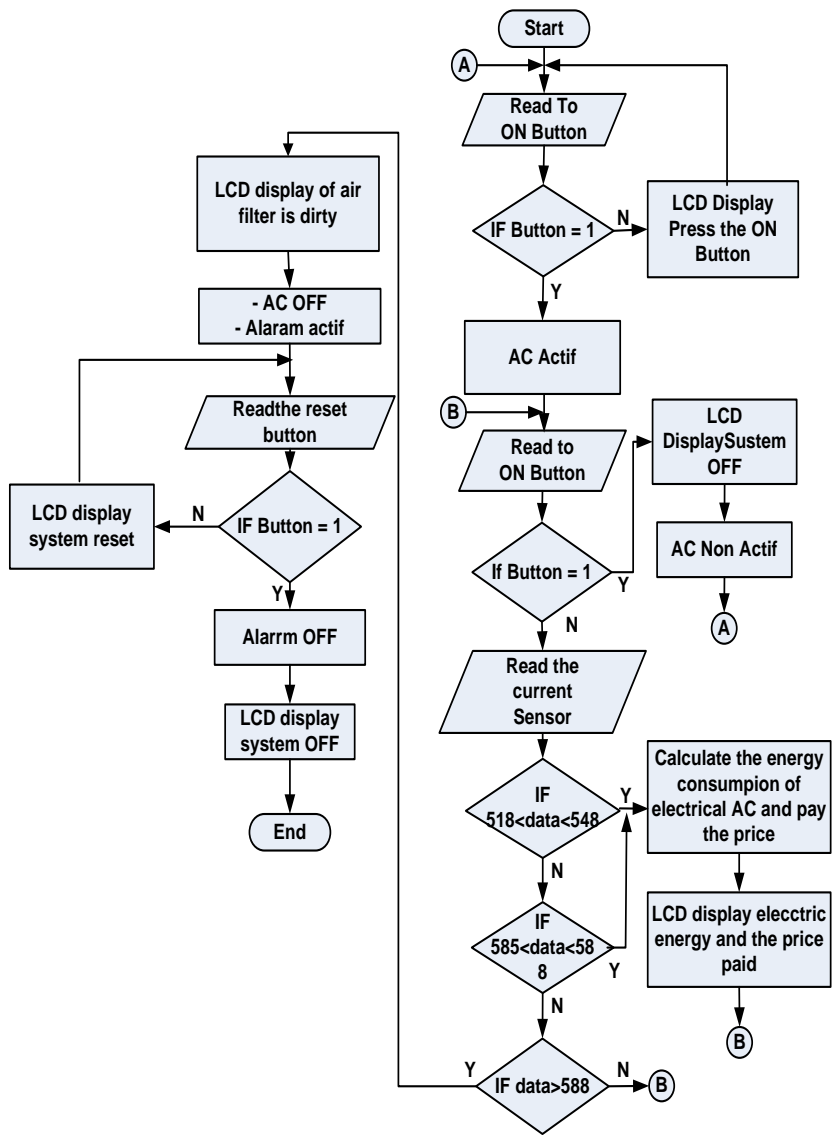

Fig. 2 Flow chart system 


\subsection{System Planning}

The design of the system is done by combining system modules such as relay driver module, driver module current sensor, alarm driver modules, input modules such as buttons and an LCD display that serves as. The modules are integrated with a microcontroller ATMega 8535 that serves as the central control of the whole system work, based workflow that is drilled into the microcontroller program ATMega 8535 . Figure 3 shows the design of the detection system air filter air conditioning.

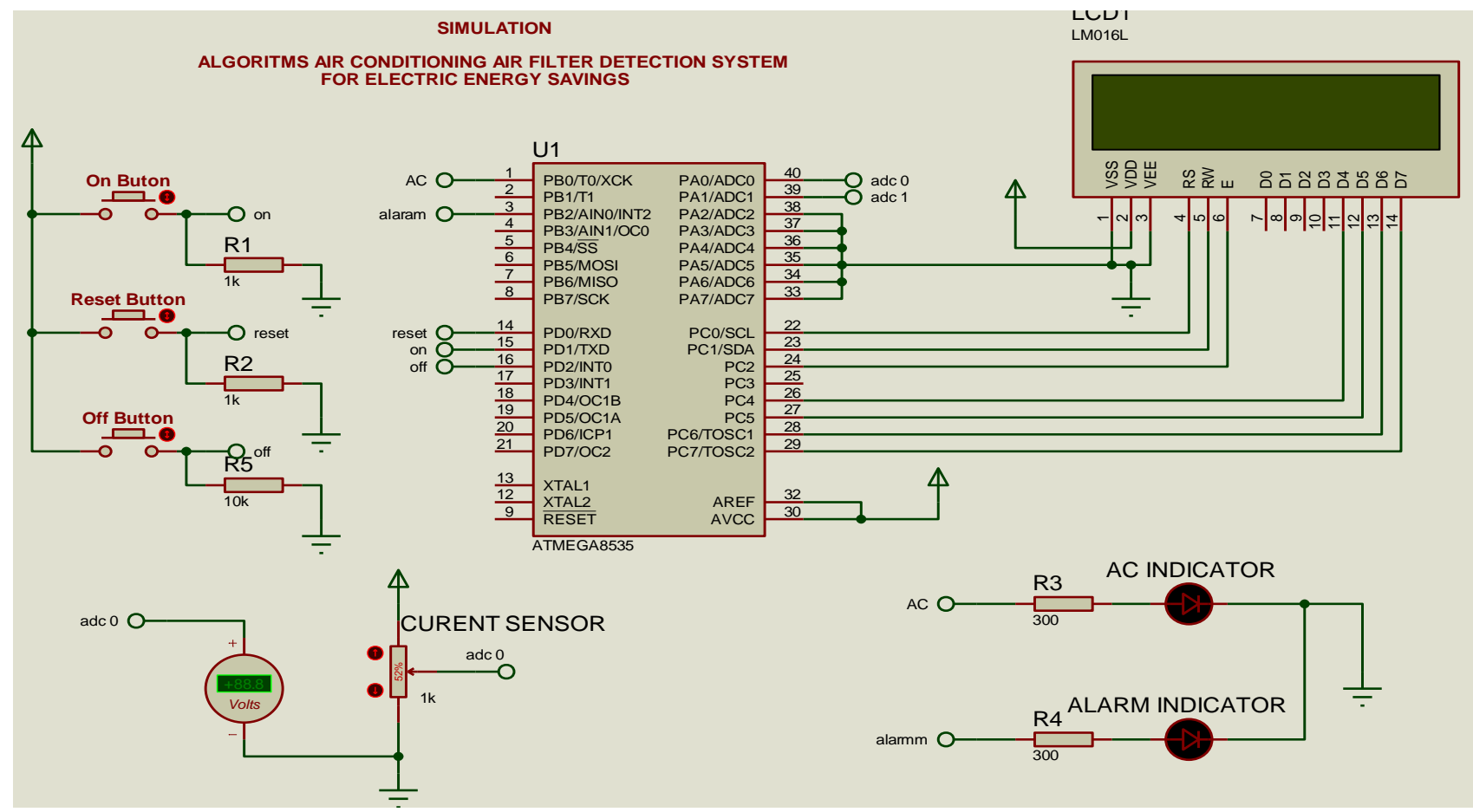

Fig. 3 Design System

\section{RESULT AND DISCUSSION}

Testing is done by simulating the system through software algorithms Proteus.
Figure 4 shows the testing process when the system is first activated.

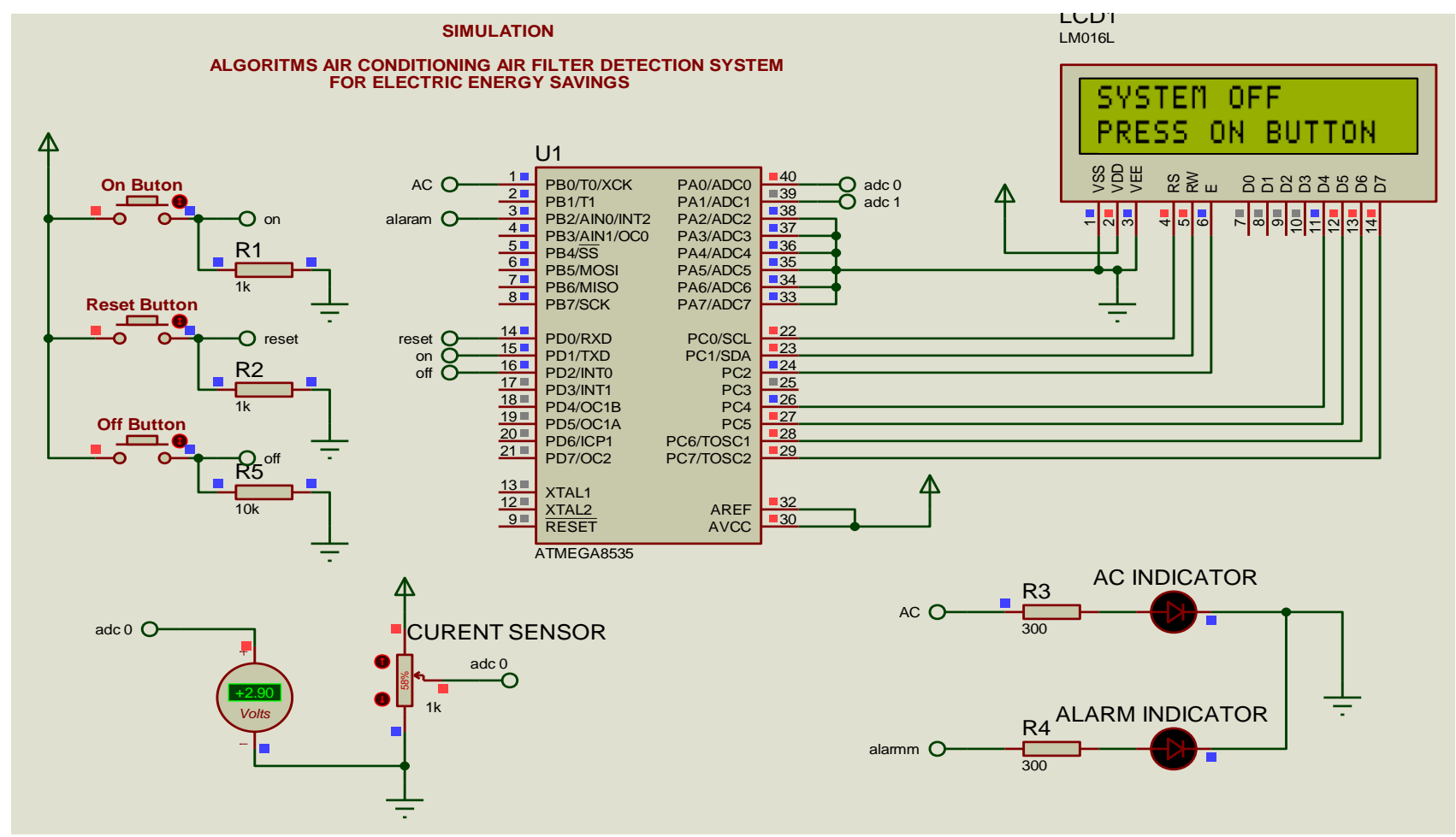

Fig. 4 System was first activated 
When the system is first activated, by pressing the ON button, air conditioning will be turned on and the current sensor will read the amount of current consumed by air conditioning equipment, then the data that will be processed by the microcontroller and display it to the LCD display. Data shown is the amount of electrical energy consumption and the price paid in rupiah. when the current sensor detects the current consumption of air conditioning equipment amounted to 0.7 amperes (use of air conditioning capacity of $0.5 \mathrm{PK}$ ), then the information is displayed to the LCD screen is the compressor off, which shows that only in indoor sections are active, while the outdoor inactive, Figure 5 shows the current state after the ON button is pressed.

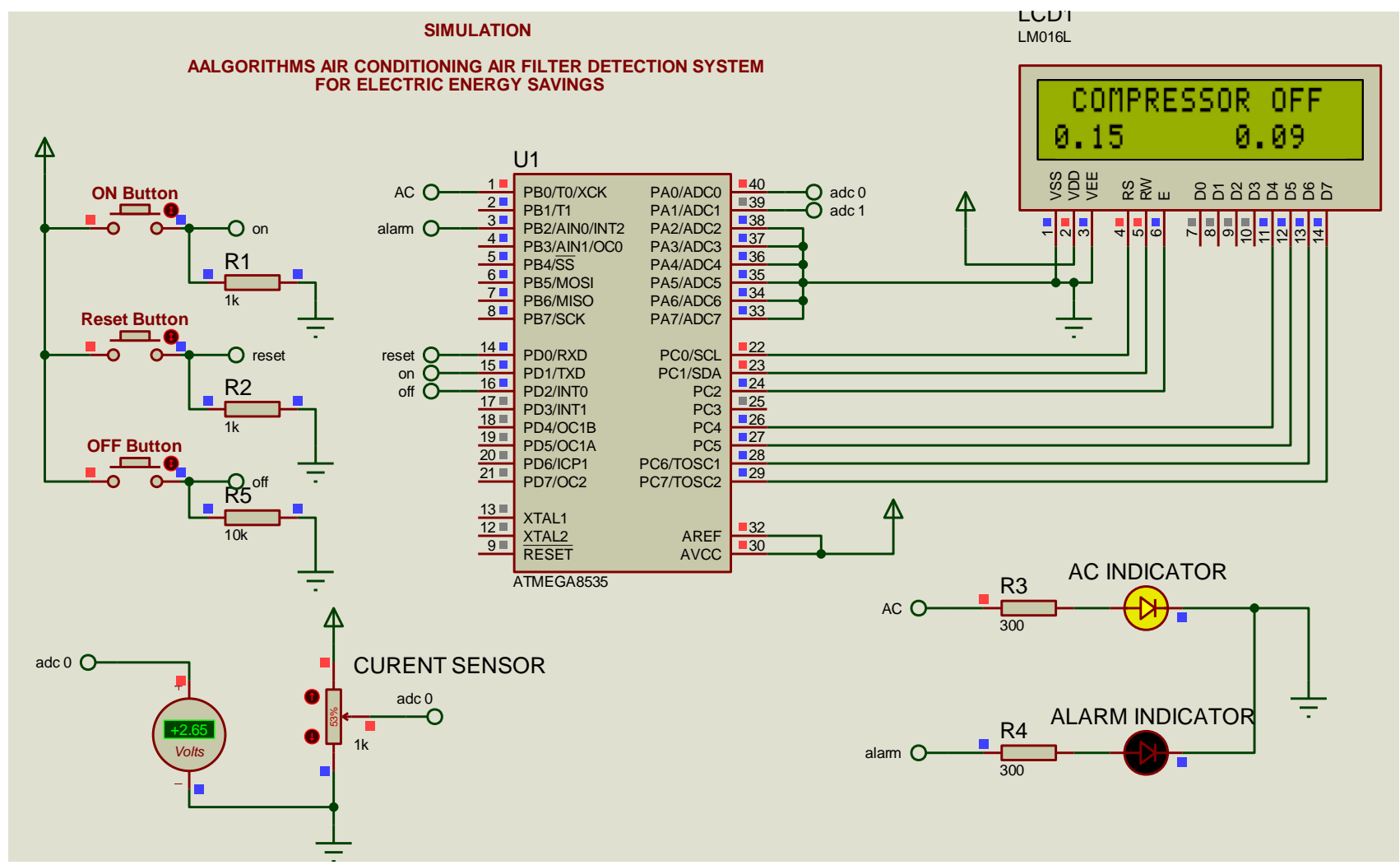

Fig. 5 after keystrokes $O N$

When the current sensor detects the amount of electric current consumption of air conditioning equipment amounted to 1.7 amperes, then the information is displayed to the LCD display is $\mathrm{ON}$ the compressor. This information indicates that the active part is indoor and outdoor of air conditioning equipment. Figure 6 shows the magnitude of the electrical energy consumption of air conditioning equipment and state of air conditioning equipment.

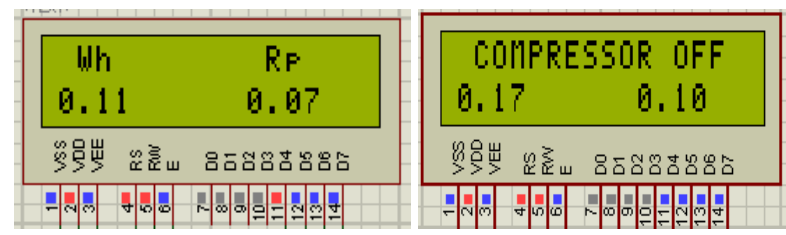

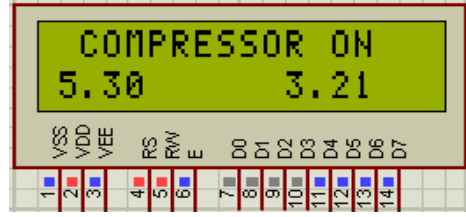

Fig. 6 Display electrical energy consumption of air conditioning equipment and state of the air conditoning.

When the system detects that the air filters of air conditioning equipment has been soiled, where testing is done by simulating a variable resistor as a current sensor, Figure 7 shows a simulation of a variable resistor as a current sensor.

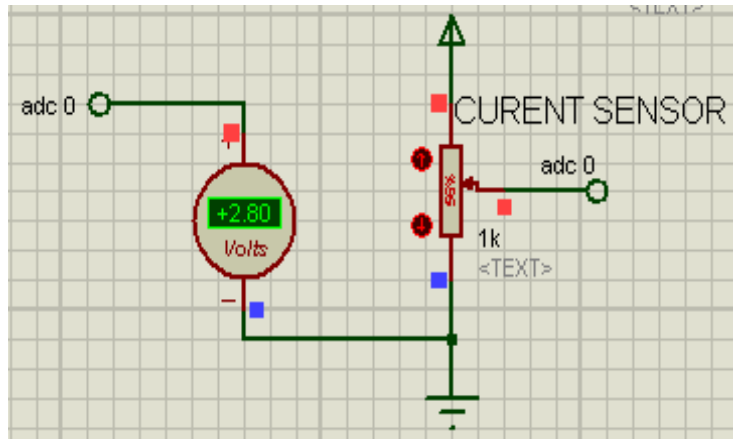

Fig. 7 variable resistor as a current sensor

When the system detects an increase in electric current consumption of air conditioning equipment of 1.85 amperes (voltage input to the ADC of the microcontroller of 2.85 volts), it is because the air filter of the air conditioning has been soiled so that the air conditioning equipment will operate continuously striving to reach room temperature according to the set point temperature, the system will turn off the air conditioning work and activate an alarm to inform the user that the air conditioning equipment maintenance needs to be done. In addition, the system will also notify the user via the display on the LCD screen that air conditioning equipment 
maintenance needs to be done in connection with the air filter was dirty. Figure 8 shows the testing process when the system detects that the air filters of air conditioning equipment has shown gross.

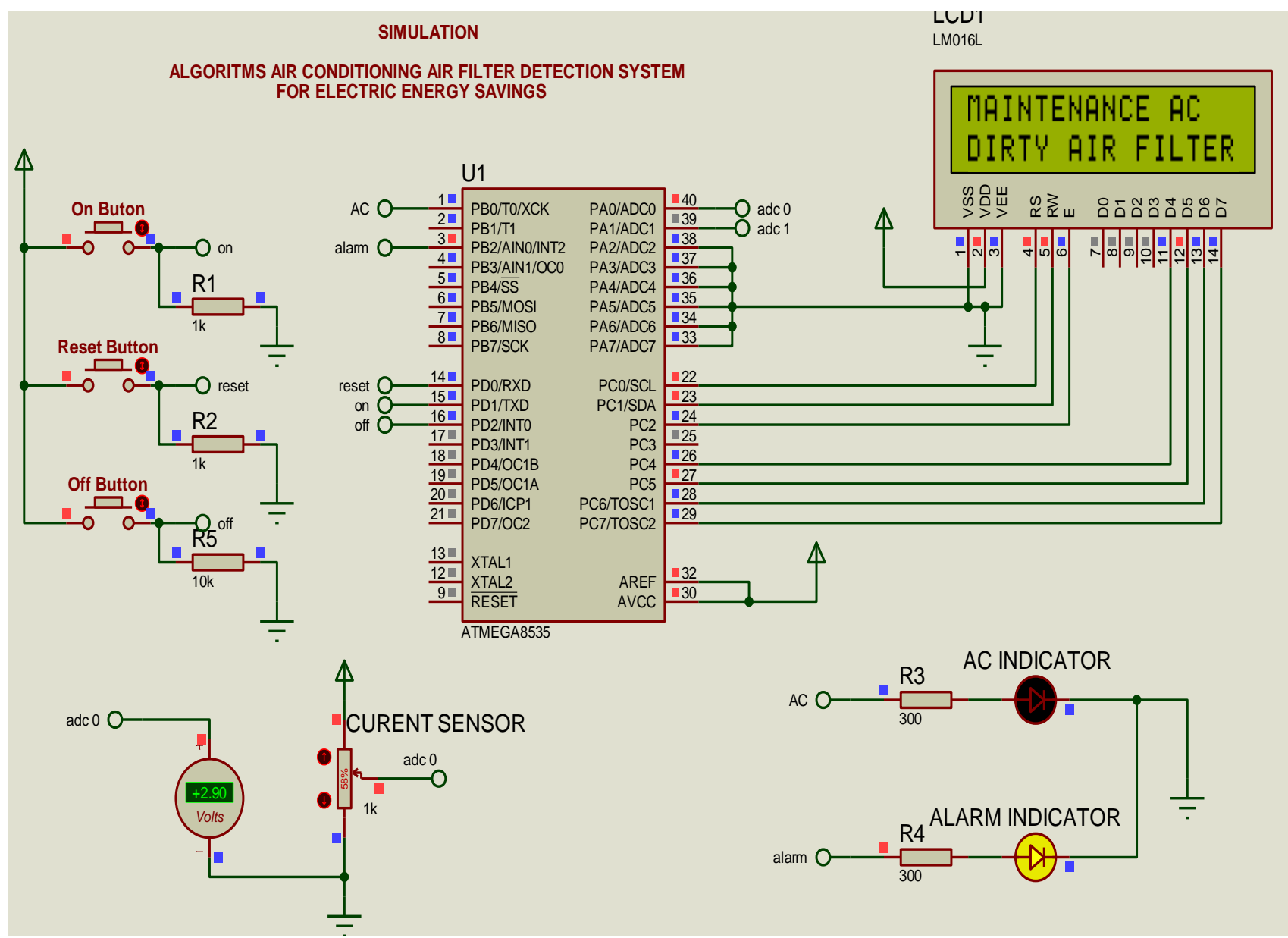

Fig. 8 Display current indicated AC air filter is dirty

When the system detects that the air filter of the apparatus of air conditioning has been dirty, then the user can know that the equipment of air conditioning needs to be treated through the indicator alarms (buzzer sound and LED lights are blink), so users can immediately perform the maintenance on the equipment air conditioning of the.

To reset the system, which needs to do is press the reset button so that the system can return to the beginning of the process.

By using Algorithm Air Conditioning Air Filter Detection System which is applied through the control equipment (system control detector soiling filter water air conditioning), can minimize the wastage of electrical energy as a result of soiling the air filter of the apparatus of air conditioning, because when the control system detects that the air filter from the equipment had been dirty (when there is an increase of 1.85 amperes of electric current, as a result of the work of air conditioning continuously), it will automatically control system will disable the working of the air conditioning equipment.

\section{CONCLUSIONS}

From the results of tests performed using Proteus program, algorithm turns on the air filter detection system of air conditioning equipment can disable the work of air conditioning equipment when it was detected that the air filter was dirty, so as to minimize wastage of electrical energy. This algorithm can also provide information to the users of air conditioning through alarm indicators (buzzer sound and LED lights are blink) and through the display LCD (Liquid Crystal Display) that the equipment of air conditioning needs to be taken care when the air filter is detected dirty, so users can know that the equipment of air conditioning needs to be treated and soon perform maintenance on the air conditioning equipment. For development, the program has been created that refers to the design of the algorithm, can be implemented through an integrated control system and mounted to the air conditioning equipment, so that the electrical energy waste caused because the dirtiness of the air filter of air conditioning equipment can be avoided.

\section{ACKNOWLEDGMENTS}

Thanks to the Ministry of Research and Technology of Technology and Higher Education, which has funded this research with competitive grants program in 2016, so as to do research and work well.

\section{REFERENCES}

[1] Allegro mikrosistem.inc. "Datasheet ACS712".

[2] Bishop, Owen. "Dasar-dasar Elektronika" Erlangga. Jakarta, 2004

[3] CodeVisionAVR V1.25.7 "User Manual” Pavel Haiduc and HP Invo TechS.R.L, 2007. 
[4] Chiou. C.B., Chu C.M. dan Lin, S.L. "The study of energisaving strategy for direct expansion air conditioning system" Energi and Buildings 40. 16601665,2008

[5] Didik Wiyono "Panduan praktis mikrokontroler keluarga AVR menggunakan DT-Combo AVR-51 starter kit dan DT-Combo AVR exercise kit' Inovative Electronics, Surabaya, 2007.

[6] Sudirman dan Winaya, I N.S. "Pengaruh Variasi Putaran Poros Kompresor Terhadap Performance Sistem" Naskah Lengkap The National Conference on Hotel Engineering - 2010, Denpasar 22 Juli 2010.
[7] Tony Hartono Bagio "Algoritma dan Pemograman" Fakultas Ilmu Komputer, Universitas Narotama Surabaya, 2007.

[8] User Manual "Intelligent Schematic Input System" Labcenter Electronics, November 2002.

[9] Widell. K.N. dan Eikevik. T. "Reducing power consumption in multi -compressor refrigeration sistems" International Journal of Refrigeration 33. 88-94, 2009.

[10] Zhou, Y.P., Wu, J.Y., Wang, R.Z. \& Shiochi, S. "Energi simulation in the variable refrigerant flow airconditioning sistem under cooling conditions" Energi and Buildings 39. 212-220, 200 